\title{
Where Will Professional Software Engineering Education Go Next?
}

\author{
Bill Davey and Arthur Tatnall \\ ${ }^{1}$ School of Business Information Technology \\ RMIT University, Melbourne, Australia \\ Bill.Davey@rmit.edu.au \\ 2 Centre for International Corporate Governance Research \\ Victoria University, Melbourne, Australia \\ Arthur.Tatnall@vu.edu.au
}

\begin{abstract}
In 1998 Lethbridge surveyed software engineering professionals and found that there were aspects of their degree that they saw as being useless to their jobs. This study was repeated in 2005 with very similar results despite a significant tightening of the research method. Inspired by this input to the curriculum development process we studied 20 years of curriculum at a University chosen for its very close ties to industry. The study showed that there has been a continual and growing move towards integrating specific technical issues into organisational context. The indication is that curriculum valued by industry will involve students being immersed in business problems rather than learning technical skills and then finding a place to apply them.
\end{abstract}

\section{Introduction}

To produce a competent software engineer takes at least 4 years of undergraduate education and a minimum time of professional experience. This means the educators must be able to look at least 4 years into the future. In many countries there is overlaid on this need for precognitive powers a strange anomaly. The general public sees the job of software engineers to be producing computer programs. The same general public in many countries have heard disturbing rumours of the off-sourcing of coding jobs to other places such as Russia or India. This is in the same climate that sees not only considerable deficit in Information and Communication Technology (ICT) professionals, but undergraduate numbers that can never be expected to meet known demands for ICT staff. A seminal point in this discussion happened in 1998 when Lethbridge [1] conducted two studies into computing and software engineering curricula. Lethbridge found, using two methods, that the same set of curriculum materials was uniformly seen as having been a waste of time by professionals. This work showed that it is possible, not only to lack foresight, but to 
continue to include curriculum elements that are no longer valid. In an attempt to allow us to see what picture should be painted of the future of the industry we have looked at the past of ICT education in an attempt to draw some trend line that will help make the future picture clear. This paper will report on a study of a sample curriculum over 20 years. The study seeks to find trends that can inform our decisions on where to take curriculum in the next 20 years.

\section{A View of the Future from the ICT Industry}

In 2006 a report to the Australian Commonwealth Government [2] underlined the value for Australia of a highly skilled ICT workforce able to make innovative use of ICT as the key to business productivity improvement. It went on to state that: "The combined impacts of the ageing workforce, changing generational patterns of work and the apparent failure of many employers to upgrade workplace skills could mean that Australia risks being unable to sustain key ICT-based economic capabilities, operations and services in the future" [2]. In particular it identified as "a major concern" what it considered as an outmoded and negative perception of ICT occupations and careers. It pointed to a poor understanding of the diversity of ICT occupations and opportunities and suggested the urgent need: "for action to address negative perceptions of ICT careers in the community which lead many young people and those who influence their career choices (such as parents, teachers, career advisers) to underestimate the opportunities available in ICT and thus to turn away from considering a career in ICT" [2].

In Australia ICT represents about $3.6 \%$ of the total workforce which is higher than for Europe (about 2.5\%) and the United States (about 2.8\%) [2].

Also as a part of this Australian Government report the Committee noted the views expressed by Gartner [3] on the future of the ICT profession. This Gartner Report predicts that by 2010 the ICT profession will be split into four main areas of expertise:

- "Technology Infrastructure and Services, with growth in service, hardware and software companies. Network design and security will remain strong everywhere, with routine coding and programming off-shored to developing economies.

- Information Design and Management, with growth in business intelligence, online consumer services, workplace enhancement. Search-and-retrieval practices and collaboration, particularly in ICT-user, systems integration and consulting companies. In this area Gartner predicts there will be a demand for professionals with linguistics, language, information design and knowledge management skills.

- Process Design and Management, involving standard operational processes (for outsourcing vendors), competitive business processes (for ICT-user companies) and design of automation software (for software vendors).

- Relationships and Sourcing Management, requiring ICT professionals to acquire skills in this area which demands strengths in managing intangibles, negotiating among different parties and coordinating outcomes among 
geographically distributed parties with different work agendas and cultures. In some instances ICT professionals in this area will serve as relationship managers between overseas service providers and domestic customers."

Gartner also notes that by 2010, six out of ten people working in ICT will be undertaking business roles based around information, process and relationships [3]. They point to four chief areas of knowledge that will inform and enrich the domains of expertise listed above [3]:

- "Technical knowledge. How does this technology work? What are its effects? How does it interact with other technologies? What are its dependencies?

- Business-specific knowledge. What makes this company tick? Businessspecific knowledge breaks down further into knowledge of enterprise objectives, operational activities, social and knowledge networks, and cultural behaviors.

- Core process knowledge. What processes fuel this company's competitive edge? In other words, which processes make this company unique?

- Industry knowledge. What forces, markets and models characterize this industry? Which parties or industries are traditional or emerging buyers and sellers? How does regulation affect this industry? Which industries does this industry resemble?" [3]
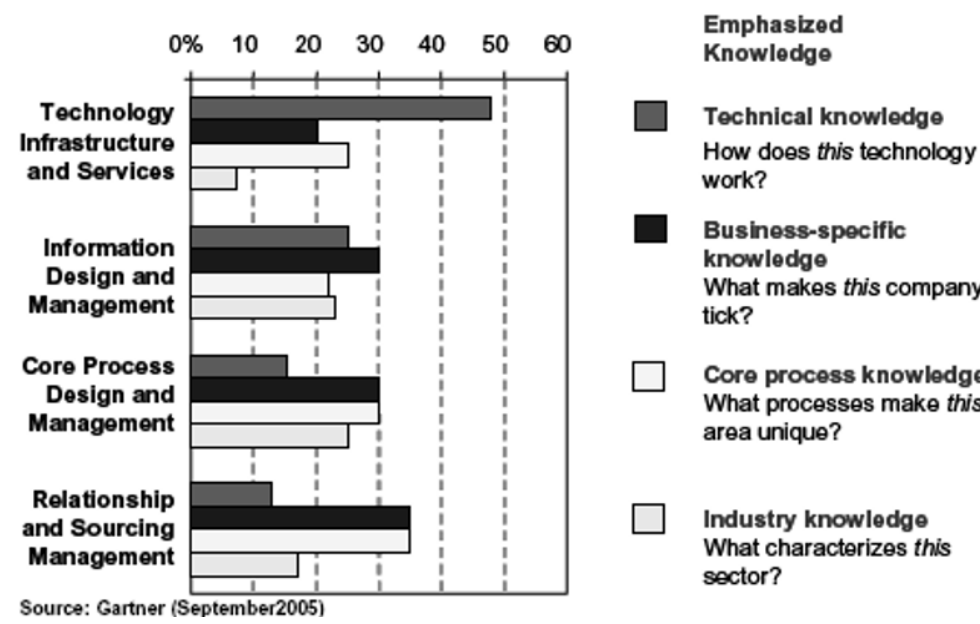

Figure 1: Relationship between areas of knowledge and domains of expertise

It is instructive to look at views from the industry itself. In Australia, over the last few years the Australian Computer Society has noted with irony the decline in University enrolments across the IT field in comparison with the growing shortage of ICT professionals in the industry [4]. In the United Kingdom (UK) in 2006 at a meeting of the Information Technology Professors, a senior technical executive from IBM responded to a question about the future of software engineering in the UK by agreeing that most of the basic programming jobs would continue to be outsourced to countries like India. He went on to stress, however, that business-related ICT jobs 
would and must remain in the country [5]. These jobs would involve areas such business analysis, and customising solutions for local businesses.

\section{Verifying a Trend}

When Lethbridge [1] found gaps in software engineering curricula it was by surveying professionals. Later work by [6] found almost identical results but made sure that the people surveyed were relevant to the University curriculum being studied by careful selection of the population. There are still two problems with this method:

- Graduates in the profession know what goes on in their workplace now. Not necessarily all workplaces, and not into the future

- The survey asks a negative question: "what do you not use?" rather than "what will you need to know?"

Our study was centred in one Australian University. Australian because that is one part of the world that is known for having introduced broader curriculum alternatives than many. For example Dieste recognises "SE-specific programs have proliferated in several countries, such as the US, the UK, Australia, and Canada. Although these programs focus on SE knowledge, they might also offer electives related to advanced CS knowledge, depending on the university. This proliferation hasn't occurred throughout the European Union.’[7]

In Australia there have been a number of traditions following different streams in the formation of institutions of tertiary education. One of these steams is that of the vocational or industrial University. This model sees a tight link between the University and industry, where undergraduates are prepared to take immediate places in industry through tailored programs. An indicator of this stream is where the University favours 'applied' research. One institution of this type was Philip Institute of Technology. In 1985 an undergraduate program was introduced at Philip Institute to provide a Bachelors degree in Data Processing. When Philip Institute later amalgamated with Royal Melbourne Institute of Technology (RMIT) this course continued as a bachelor degree in Business Computing. We use this program as a case since there is the suspicion that the programs here are more closely influenced by what the direct needs are in the local industry, rather than by more theoretical consideration within the various disciplines that make up software engineering. The program has always included compulsory paid employment after two years of study and before the final year. This period of employment of all undergraduates means, among other factors, that the program is tested by current students every year against the ability to perform in up to 150 workplaces (one for each enrolled student in each year level.)

\section{The Sample Points}

To draw our trend lines we need a number of points spread out over the short history of our discipline. It is not very sensible to start much before a complete 
degree program was introduced and so we start with the program description of a whole program introduced in 1986 and the writings of 1984 and 1985 that were the principal influences for that course. We then describe the programs that were offered in 1990 and 1995 and compare them with the 2000 programs and the newly accredited program that will be delivered starting in 2008. This sample of approximately 5 years, keeping the environment of the University constant, provides some lessons for what might happen over the next 5 years.

\section{Results}

To attempt to find some patterns across the history of this one program, each of the course description documents was read, with attention to both stated intentions of the program and actual contents of the courses that made up the programs. The aims of the program have remained remarkably stable over the 20 years of the study. When first proposed in 1985, the program was intended "to provide a sound understanding of information structuring and processing concepts, system building techniques and computing technology as a framework to facilitate the continual development of professional competence" [8]. As we will see, this was interpreted in the subject construction in a very technical way. However, from the very first, these programs were intended to ally as closely as possible to industrial needs. As the program developed from an initial offering the aim continued to be fairly stable. By 1990 the program was "to provide the opportunity for the student to apply concepts and procedures and to develop technical computing skills on assignments representative of those in industry, commerce or government" [9]. The amalgamation of the two institutions to become a university came with a move to focus more on the application of skills to program aims with an almost complete lack of the word skill. In 1995 the program was to "produce competent graduates with a level of professionalism appropriate to work in business computing and information systems" [10]. The current program talks about skills with a totally different meaning, but maintains the close ties to industry. In 2007 "The program allows you to develop both generic business and specific business information systems capabilities through experiential learning to meet current and future expectations of employers. By applying real and relevant knowledge, the program is aimed at developing you as a highly skilled, 'well-rounded' ICT professional" [11]. The changes that have happened over the 20 years have also come about through consideration of the same set of forces. The current proposal for 2008 reflects practices recorded for previous changes to the program: "proposed changes are the outcome of a series of workshops involving academics involved in the delivery of the program. Documentation prepared for the 2005 Australian Computer Society Accreditation Program Review Process was also reviewed together with its subsequent recommendations for improvements. Also sourced was literature pertaining to the required skills and knowledge required of future ICT professionals. Subsequent discussions drew on the participants' experiences and research, collected through conversations and feedback from students, discussions with employers on co-op visits, and readings from industry reports and research papers." [11] 


\section{Classifying Subjects}

The analysis of program components consisted of examining each subject in each incarnation of the program. The examination sought to identify some useful distinction between subjects so that a track could be made from 1985 to the present day. A distinction that became immediately obvious was that between subjects built around a particular technology: COBOL programming (such as the first versions of the subjects Commercial Programming A and B), Networking and Machine Language subjects, and those that generally taught 'how to run a computer'. Alternatively there were always subjects built around means of identifying and applying technology to business problems. These subjects still often contained some technology based skill, but the descriptions and syllabi were oriented around the needs of the problem area rather than the technology solution. We decided to call these 'technology' or 'integrative' subjects, integrative in that the technology was to be integrated into a study involving the finding of solutions. Over the years the program has generally included 24 subjects, plus a year of work integrated learning giving students a work load of 8 subjects each year. As a degree in the Faculty of Business, there have always been a number of compulsory non-IT subjects and a varying number of elective subjects that must be taken from the IT stream. We took as an indicator of trend the number of elective subjects offered as an indication of the perceived educational need of students. Table 1 (below) shows the breakdown of subjects over the period studied:

Table 1: Classification of subjects taught from $1985-2008$

\begin{tabular}{|c|l|l|l|l|l|l|}
\hline Year & $\begin{array}{l}\text { Core } \\
\text { technology } \\
\text { subjects }\end{array}$ & $\begin{array}{l}\text { Elective } \\
\text { technology } \\
\text { subjects }\end{array}$ & $\begin{array}{l}\text { Core } \\
\text { integrative } \\
\text { subjects }\end{array}$ & $\begin{array}{l}\text { Elective } \\
\text { integrative } \\
\text { subjects }\end{array}$ & $\begin{array}{l}\text { Total } \\
\text { technology } \\
\text { subjects }\end{array}$ & $\begin{array}{l}\text { Total } \\
\text { integrative } \\
\text { subjects }\end{array}$ \\
\hline 1985 & 6 & 5 & 0 & 3 & 11 & 3 \\
\hline 1990 & 9 & 5 & 3 & 3 & 14 & 6 \\
\hline 1995 & 3 & 8 & 5 & 5 & 11 & 10 \\
\hline 2000 & 3 & 8 & 5 & 6 & 11 & 11 \\
\hline 2005 & 3 & 3 & 7 & 13 & 6 & 20 \\
\hline 2008 & 0 & 2 & 13 & 11 & 2 & 24 \\
\hline
\end{tabular}

The first thing to note about this table is that the total number of IT subjects rapidly rose in the first five years. From the original 14 subjects thought to cover all of undergraduate IT to a total of 20 subjects was a large jump in the scheme of curriculum change. Subjects added to the list included another language (FORTRAN), Assembly Language and Graphics Programming and a second computer hardware subject. The only change in integrative subjects was to take the 3 electives in Business Information Systems and make them compulsory. By 1995 the move to cover every technical skill had reached its peak with VB, PICK, COBOL, Pascal and $\mathrm{C}$ being taught as programming languages. Graphics programming had been dropped, as not being commercially relevant, and commercial programming 
had changed in fundamental nature. It became and was now called Applications Development. The subject content no longer was written around syntax of a programming language, but described the process of determining requirements and planning a system to meet those professionals using a language. The next significant change happened in 2005 after a major review of the program. At this change almost all the programming subjects delivering skills narrowly defined by a programming language were removed. Two networking subjects were sufficiently oriented to the technology that these were defined as technology subjects, despite a significant move to problem solving within the technological environment.

\section{Conclusion}

In 1986 the program was intended to "provide a professionally recognized business oriented data processing course" [8]. By 1995 students found "your job can involve the planning, design, implementation and management of information systems that your organization depends upon" [8]. The current student is told that they will be popular because "companies choose RMIT graduates because of their IT skills and business acumen" [12]. There is now a specific set of envisioned outcomes for graduates. They can look forward to positions like the following: "Typical positions include business analyst; Internet service provider; database designer and administrator; systems operations manager; systems analyst; IT consultant; programmer/analyst; information centre manager; client server administrator; network administrator; object oriented systems developer; training officer in IT area; applications developer; software engineer; user liaison officer; computer marketing executive; and information systems manager" [12]. So the first trend line we see is one from a focus on the data to a focus on the business. This tells educators to focus even more in the future on understanding the impact of technology rather than the intricacies of a particular technique. It also advises us to market what we do for students in terms of solutions rather than skills. Tell parents and high school students what our graduates have done for their companies, rather than how much fun it is to write computer programs, show them pictures with clients rather than with terminals and develop programs of study that integrate learning rather than isolate discipline lines. This also fits well with what the industry suggests is the future of the IT professional in countries like Australia. Gartner [3] identifies four areas of knowledge that they predict will be needed in the future:

- Technical knowledge.

- Business-specific knowledge

- Core process knowledge.

- Industry knowledge.

If we look at the change in our sample over 20 years it is clear that this set of four areas of knowledge is what we have been moving towards. 


\section{References}

1. Lethbridge, T. A Survey of the Relevance of Computer Science and Software Engineering Curricula. in Proceedings of the 11th International Conference on Software Engineering. 1998. Silver Spring MD: IEEE Compuetr Society Press.

2. Department of Communication; Information Technology and the Arts, Building Australian ICT Skills: Report of the ICT Skills Foresighting Working Group. 2006, Department of Communication, Information Technology and the Arts: Barton, ACT.

3. Gartner, The IT Professional Outlook: Where Will We Go From Here? 2005, Gartner: Orlando, Florida.

4. Australian Computer Society. ICT Professionals Shaping Our Future. 2007 [cited November 2007]; Available from: http://www.acs.org.au/.

5. Thompson, J.B., The Future of ICT Education in the UK. 2006: Newcastle, UK.

6. Kitchenham, B., et al., An investigation of software engineering curricula. The Journal of Systems and Software, 2005. 74(3): p. 325.

7. Dieste, O., N. Juristo, and Ana M. Moreno, How Higher-Education Systems Influence Software Engineering Degree Programs. IEEE Software, 2004. 21(4): p. 78.

8. Philip Institute of Technology, A Submission for Accreditation to the Accreditation Board for a UG1 Bachelor of Business (Data Processing). 1985.

9. Philip Institute of Technology, 1990 Handbook. 1990, Bundoora: PIT Publishing.

10. RMIT, Faculty of business undergraduate and post graduate proghrams 1995. 1995, Melbourne: RMIT.

11. Dick, M., Draft Program Guide BP138 Bachelor of Business (Business Information Systems). 2007, RMIT University: Melbourne Australia. p. 58.

12. RMIT, Program Guide BP138 Bachelor of Business (Business Information Systems. 2000. 